\title{
La activación inmune del tejido adiposo pardo y sus efectos sobre la obesidad
}

\author{
Arturo Orrego M.
}

Médico Internista Endocrinólogo, Miembro Honorario de la

Asociación Colombiana de Endocrinología, Diabetes y

Metabolismo.

Correo electrónico: stellabeltran@yahoo.com

Fecha de recepción: 25/09/2017

Fecha de aceptación: 11/10/2017

\section{Introducción}

S egún las últimas estadísticas de la Organización Mundial de la Salud, la prevalencia mundial de obesidad, definida por la fórmula índice de masa corporal (IMC) $>30 \mathrm{~kg} / \mathrm{m}^{2}$, se ha duplicado desde $1980 \mathrm{y}$ al menos 2,8 millones de personas mueren cada año como consecuencia de la obesidad. Se espera que estas cifras aumenten en la próxima década. La obesidad trae como complicaciones, hipertensión, dislipidemia y resistencia a la insulina.

Como consecuencia de estas asociaciones se presentan enfermedades de las arterias coronarias, ateroesclerosis, hígado graso, diabetes tipo 2, cáncer y enfermedades degenerativas $^{(1)}$. Se sabe que el sistema inmune juega un papel esencial en la patogénesis de la obesidad. En los últimos años se está investigando intensamente con el fin de detectar los factores patogenéticos involucrados en la relación de la inmunidad con la obesidad y en esa forma poder descubrir procedimientos nuevos en la terapia de esta entidad. Recientemente, se descubrió que la activación del tejido adiposo pardo y del beige producía un aumento del consumo de energía, pérdida de grasa y disminución de la inflamación del tejido adiposo ${ }^{(2)}$. Como interesante se ha puesto en evidencia que el funcionamiento del tejido adiposo pardo (TAP) y el beige están sujetos a regulación inmune $\mathrm{e}^{(3-6)}$, hecho que obliga a investigar nuevos conocimientos.

\section{Tejido Adiposo Pardo (TAP)}

Se conoce que el tejido adiposo blanco (TAB), sirve de depósito de energía; en cambio el tejido adiposo pardo juega un papel esencial en el consumo o desgaste de energía. El tejido graso pardo convierte la energía de la glucosa y de los ácidos grasos en calor, lo que contribuye a mantener la temperatura corporal $^{(7)}$. La regulación de la temperatura corporal es esencial para conseguir que las funciones celulares y los procesos fisiológicos puedan continuar en medio de un ambiente frío ${ }^{(8)}$. Los depósitos de grasa parda (TAP) en humanos se localizan preferencialmente en las zonas supraclaviculares y en la nuca, pero también a lo largo de las vértebras de la aorta y cerca de los riñones (tabla 1). En roedores, la mayoría de los depósitos del tejido adiposo pardo se encuentran en la zona interescapular, y en menor proporción en la axila, la región cervical, perirrenal y periaórtica. La abundancia de mitocondrias y la vascularización extensa producen el color particular pardo de estas estructuras $^{(10,11)}$.

Tabla 1. Depósitos del TAP en humanos y ratones. Los humanos recién nacidos tienen depósitos interescapulares de TAP que regresan con la edad. Los humanos adultos tienen depósitos de TAP en las regiones supraclaviculares y en la nuca.

Depósitos pequeños existen a lo largo de la aorta, vértebras

y riñones. En los ratones, tejidos TAP se encuentran en las regiones cervical, axilar interescapular, periaórtica y perirrenal.

\begin{tabular}{l|l|l} 
Niños & Humanos adultos & Ratones \\
\hline Interescapular & Nuca & Cervical \\
\hline & Supraclavicular & Axilar \\
\hline & Periaórtico & Interespular \\
\hline & Paravertebral & Periaórtico \\
\hline & Perirrenal & Perirrenal \\
\hline
\end{tabular}

El tejido adiposo pardo está inervado abundantemente por el sistema simpático e irrigado extensamente, lo que permite la suplencia de oxígeno y el transporte de calor. El tejido adiposo pardo tiene múltiples depósitos de grasa en vesículas, lo que facilita la suplencia rápida de energía, y un extenso número de mitocondrias que producen calor (figura 1).

El frío activa el hipotálamo que estimula el sistema simpático del tejido adiposo pardo (TAP), lo que trae consigo la liberación, de noradrenalina, la cual se une a receptores beta-3 adrenérgicos presentes en la grasa parda, pero también en el tejido adiposo blanco (TAB) (figura 1) ${ }^{(12,13)}$. La estimulación con el frío de los receptores beta-3 adrenérgicos tienen efec- 
Figura 1. Activación de los adipocitos pardos por el frío. El frío activa el hipotálamo, el cual a su vez activa el sistema nervioso simpático, con la liberación de noradrenalina, la cual se une a receptores beta adrenérgicos en los adipocitos pardos. Como resultado se presenta lipólisis intracelular, degradación de los ácidos grasos por beta-oxidación,consumo de energía y reducción de peso.
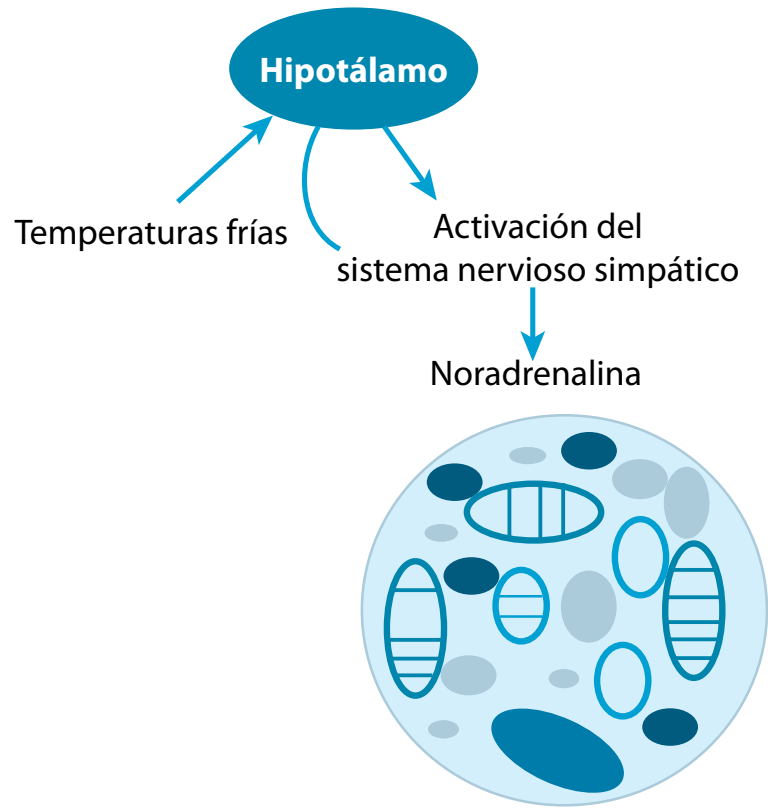

Activa la lipólisis y la oxidación de ácidos grasos

tos agudos y crónicos sobre el TAP. La termogénesis aguda resulta en lipólisis, degradación de ácidos grasos, de captación de glucosa y activación de proteínas-1 desacopladoras, capaces de inhibir la fosforilación oxidativa ${ }^{(14)}$. El TAP expresa abundante aumento de la UCP1, una proteína mitocondrial que desacopla la fosforilación oxidativa, en la síntesis del adenosiltrifosfato (ATP), lo que trae consigo la disipación de la energía en calor $^{(15)}$.

\section{Adipocitos blancos, beige y pardos}

Se han descrito dos tipos de adipocitos pardos, de diferentes orígenes. El tipo clásico, que se encuentra en ratones, en la zona interescapular, perirrenal y axilar (tabla 1) y el llamado tejido adiposo brite o beige que se encuentra dentro del tejido adiposo blanco (TAB). Como en el humano los depósitos del tejido adiposo pardo (TAP) son escasos, es difícil obtener medios para estimular la formación de los adipocitos beige dentro del tejido adiposo blanco (TAB), que gozan de las características funcionales similares a las células adiposas pardas. Una diferencia importante entre las dos células es que la clásica célula adiposa parda expresa dentro de sí UCP1, en cambio la célula adiposa beige únicamente la expresa durante estímulos apropiados, tales como el frío y el estímulo de los receptores beta adrenérgicos ${ }^{(16-18)}$. El aumento en la biogénesis de los adipocitos beige puede contribuir al incremento del gasto de energía, mejorar los parámetros metabólicos y de tolerancia al frío.

Los adipocitos beige están presentes dentro de las células adiposas blancas y cuando están presentes en cantidad suficiente, aumentan el consumo de energía y por tanto contribuyen a la reducción de la grasa ${ }^{(19-21)}$.

Los adipocitos beige se originan en las células adiposas blancas por la vía de la transdiferenciación ${ }^{(22-24)}$. Sin embargo, otros estudios demostraron que las células adiposas beige se pueden originar de novo en ciertos precursores ${ }^{(25)}$.

La vasculatura puede ser otro importante medidor de la formación de adipocitos beige, los cuales como los adipocitos pardos, están ampliamente vascularizados; pueden obtener fácilmente oxígeno, nutrientes y transportar calor $^{(26)}$. El ejercicio, el tratamiento con beta-3 adrenérgicos y análogos PPAR gama, no sólo inducen cambios beige, sino que también aumentan la angiogénesis. El exceso de expresión del factor de crecimiento vascular endotelial aumenta la vascularización de las células adiposas pardas.

La transformación de los adipocitos pardos en adipocitos blancos también ocurre. La denervación simpática, la edad y el excesivo consumo de energía hace que los adipocitos pardos acumulen grasa, produciendo adipocitos blancos ${ }^{(27,28)}$.

Aunque el mecanismo de cómo se transforman las células adiposas pardas en blancas no se conoce, se cree que el factor de crecimiento endotelial vascular pudiera desempeñar un factor importante en esta génesis; la obesidad disminuye la expresión del factor de crecimiento endotelial vascular y la ausencia de este factor resulta en blanqueamiento del $\operatorname{TAP}^{(25)}$.

\section{Tejido adiposo pardo en roedores}

Van den Berg y cols ${ }^{(25)}$ resumieron magistralmente lo conocido hasta el momento sobre el tejido adiposo pardo, en roedores.

El frío estimula el tejido adiposo pardo para aumentar el consumo de energía en ratones, de donde dedujeron que los adipocitos pardos pueden utilizarse como fuente para el control del balance energético del organismo, de la adiposidad y de la obesidad.

En ratones, además del frío, una variedad de estímulos pueden activar los adipocitos pardos y además promover la formación de adipocitos beige, y el desarrollo de células similares a los adipocitos pardos dentro del tejido adiposo blanco por medio de transdiferenciación o de novo de células precursoras.

Está claro que en humanos también existen depósitos de adipocitos pardos, aunque el blanquecimiento de las células 
pardas también puede ocurrir en respuesta al exceso de depósitos de grasa y a otros factores ${ }^{(25)}$.

El aumento de los adipocitos pardos mejora el metabolismo, en cambio su disminución está asociada con la disfunción metabólica.

La obesidad originada en el tejido adiposo blanco se caracteriza por la infiltración de células inmunes, lo que inicia un grado bajo de inflamación, pero el sistema inmune juega un papel importante en la presentación, función y actividades de los adipocitos pardos y en la formación de los adipocitos beige a partir de los adipocitos blancos del tejido graso.

Las drogas capaces de transformar los adipocitos blancos en beige o de estimular las células pardas por vía inmunológica tienen potencial para tratar la obesidad y sus dañinas secuelas, como la diabetes tipo 2 y las enfermedades cardiovasculares.

\section{El TAP y la obesidad en humanos}

Se creyó inicialmente que las células adiposas pardas en humanos únicamente se presentaban en recién nacidos, pero recientemente se demostraron en adultos (tabla 1) ${ }^{(9,25)}$. Con la tomografía por emisión de positrones (PET), utilizando ${ }^{18}$ Fluorodeoxiglucosa (FDG) y la TAC se detectaron zonas activas gamagráficamente en adultos, cuyas biopsias comprobaron que eran tejido adiposo pardo.

En estudios de humanos adultos, cuando se compararon los perfiles de la expresión genética de los adipocitos blancos, los beige y los pardos, sugirieron que los adipocitos pardos estaban únicamente compuestos de adipocitos beige ${ }^{(21,25)}$, en cambio otros autores encontraron marcadores propios de los adipocitos pardos ${ }^{(25)}$. Es posible que los adipocitos beige permanezcan en adultos, aunque la hipotermia sea una menor amenaza que en los recién nacidos. Aún se desconoce completamente sobre la capacidad de los adipocitos beige de cambiar de un estado de conservación de los depósitos de grasa a uno de disipación de energía ${ }^{(25)}$.

A medida que se descubrió la presencia del TAP por medio de la PET/TAC en adultos, se observó una correlación negativa con el índice de masa corporal y el porcentaje de grasa ${ }^{(9)}$.

Como la estimulación de los adipocitos pardos resulta en incremento del consumo de energía, es posible que este efecto se pueda utilizar como fuente para el control del balance de la energía del organismo, de la adiposidad y la obesidad en humanos. Como interesante, la exposición repetida al frío, en humanos aumenta la actividad de las células grasas pardas. El protocolo de aclimatación al frío incluye la exposición por 6 horas durante 10 días consecutivos o diariamente a $17^{\circ} \mathrm{C}$ por 2 horas durante 6 semanas. Con la utilización de estos protocolos fue posible aumentar el volumen del tejido pardo en $37 \%$ o de incrementar la captación de FDG en $60 \%$ y disminuir la grasa en humanos ${ }^{(2)}$. Mientras más tejido graso pardo tenga el individuo exhibirá menores concentraciones de glucemia, una homeostasis de la glucosa más normal y mayor sensibilidad a la insulina ${ }^{(29,30,31)}$. El aumento de actividad del TAP en humanos, se acompaña de menos riesgo para enfermedad coronaria ${ }^{(31)}$. Los efectos del tratamiento antiobesidad por estímulo del TAP en humanos, no se han estudiado en detalle. Se conocen ciertos compuestos para tratar la dislipidemia, la hiperglucemia y para descender los triglicéridos en sangre, como la metformina, el rimonabant, el silate y los agonistas de los receptores GLP-1, activadores de la grasa parda en ratones.

\section{El efecto del TAP en la obesidad}

Con el descubrimiento de los adipocitos pardos en humanos adultos por la PET/TAC comenzó a apreciarse que la presencia de las células adiposas pardas, detectada a través de la captación con ${ }^{18}$ Fluorodeoxiglucosa (FDG), mostraban una correlación negativa con el índice de masa corporal y el porcentaje de grasa $^{(9,29)}$. En un estudio de 2000 gamagrafías PET/ TAC, seleccionadas al azar, se demostró una frecuencia mayor de TAP funcionalmente activas en mujeres y una correlación negativa con la edad, el índice de masa corporal, con el uso de betabloqueadores y la temperatura exterior en el minuto de realizar la escanografía y las estaciones ${ }^{(25)}$.

Debido a que la estimulación de las células adiposas pardas trae consigo un aumento del gasto de energía, este tejido graso puede servir como órgano efector en el control del balance general de energía, de la adiposidad y de la obesidad.

De forma interesante, la exposición repetida al frío puede aumentar la actividad del TAP. Entre los protocolos utilizados efectivamente en la aclimatación de los pacientes están: la exposición al frío durante 6 horas por 10 días consecutivos o una exposición por 2 horas diarias durante 6 semanas, a $17^{\circ} \mathrm{C}$. Utilizando estos protocolos fue posible aumentar el volumen del tejido adiposo pardo en un 37\% o aumentar la captación de ${ }^{18}$ Fluorodeoxiglucosa en un $60 \%$ y disminuir la masa grasa en humanos ${ }^{(2)}$.

Todavía los estudios sobre la utilidad de la activación de los adipocitos pardos y la transformación del tejido adiposo blanco (TAB) en tejido adiposo beige son escasos pero se esperan muchos más en proceso. Se ha demostrado que factores proangiogénicos estimulan la proliferación de los adipocitos beige en humanos, los que al ser trasplantados en ratones mejoran el metabolismo de la glucosa ${ }^{(25)}$. Como interesante, los humanos con abundantes células adiposas pardas presentan niveles de glucemia más bajos, homeostasis de la glucosa normal y un aumento de la sensibilidad a la insulina ${ }^{(30,31)}$. El aumento de la grasa parda supraclavicular, medida por PET/ TAC está inversamente asociada con la inflamación arterial y el riesgo reducido de eventos cardiovasculares ${ }^{(32)}$. Como digno de anotar es que los habitantes del sur de Asia tienen una mayor prevalencia de hiperglucemia, dislipidemia y enferme- 
dades cardiovasculares y una cantidad menor de tejido adiposo pardo. Los efectos sobre los adipocitos pardos con tratamientos antiobesidad no se han estudiado en detalle, pero algunos hallazgos sugirieron mecanismos mediados por los adipocitos pardos con algunas terapias. Ciertos compuestos utilizados en humanos en el tratamiento de la hiperglucemia, la dislipidemia de los triglicéridos, tales como la metformina, rimonabant, salsalato y los agonistas del GLP-1, activan el tejido adiposo pardo en ratones ${ }^{(33,24)}$.

\section{Activación de los adipocitos pardos y la transformación de los adipocitos blancos en adipocitos beige. El papel jugado por el sistema inmune}

Se ha demostrado que los macrófagos juegan un papel en la termogénesis ${ }^{(3)}$. La exposición aguda de ratones al frío estimula los macrófagos M2, de efectos antinflamatorios a producir tiroxina hidroxilasa, enzima necesaria en la síntesis de catecolaminas. Esto resulta en la liberación de norepinefrina, la que se une a los receptores beta-3 adrenérgicos, localizados en el tejido adiposo pardo. Como efecto, las células adiposas blancas son activadas, tal como lo demuestra la inducción de ciertos genes Ucp1 y otros genes termogénicos. Otros estudios sugieren un efecto menos pronunciado de los macrófagos en la termogénesis de los adipocitos pardos y mayor compromiso en la transformación de los adipocitos blancos en adipocitos beige. Especialmente los macrófagos M2 son activos en la formación de adipocitos beige a partir del tejido adiposo blanco subcutáneo.

No solamente los macrófagos producen tiroxina hidroxilasa, sino que también producen catecolaminas y expresan receptores beta- 2 adrenérgicos capaces de controlar por fenómenos de autorregulación los niveles de catecolaminas ${ }^{(5)}$. La grasa parda está copiosamente inervada por el sistema nervioso simpático, al mismo tiempo expresa abundancia en las enzimas sintetizadoras de catecolaminas ${ }^{(5)}$.

Se ha demostrado que la inducción de la grasa blanca subcutánea a termogénica por la producción de noradrenalina por los macrófagos es debida a los eosinófilos, vía IL-4, IL-13 y STAT6 ${ }^{(5)}$ (figura 2). La meteorina es responsable de la inducción de la secreción de interleucinas por eosinófilos. La meteorina es liberada por los músculos esqueléticos durante el ejercicio y por el tejido adiposo durante la exposición al frío. No tiene efecto directo sobre la grasa parda, pero estimula los eosinófilos a producir interleucina-4 (IL-4), la cual activa los macrófagos para aumentar la expresión de genes termogénicos y antinflamatorios ${ }^{(25)}$.

Figura 2. Remodelación del tejido adiposo blanco subcutáneo en adipocitos beige por acción inmunológica inducida por el frío. Las ILC2s son muy importantes en la transformación de los adipocitos blancos en adipocitos beige IL-33s mantienen las ILC2s para producir el péptido MetEnk, el cual regula UCP1 en el tejido adiposo blanco. IL-33 también incrementa las células T en el tejido adiposo blanco. Las células T contribuyen a la homeostasis de la glucosa. Las ILC2s secretan IL-5 y IL-13, que estimulan los eosinófilos a producir IL-4, la cual directamente o por vía de los macrófagos M2 estimulan la producción de noradrenalina.

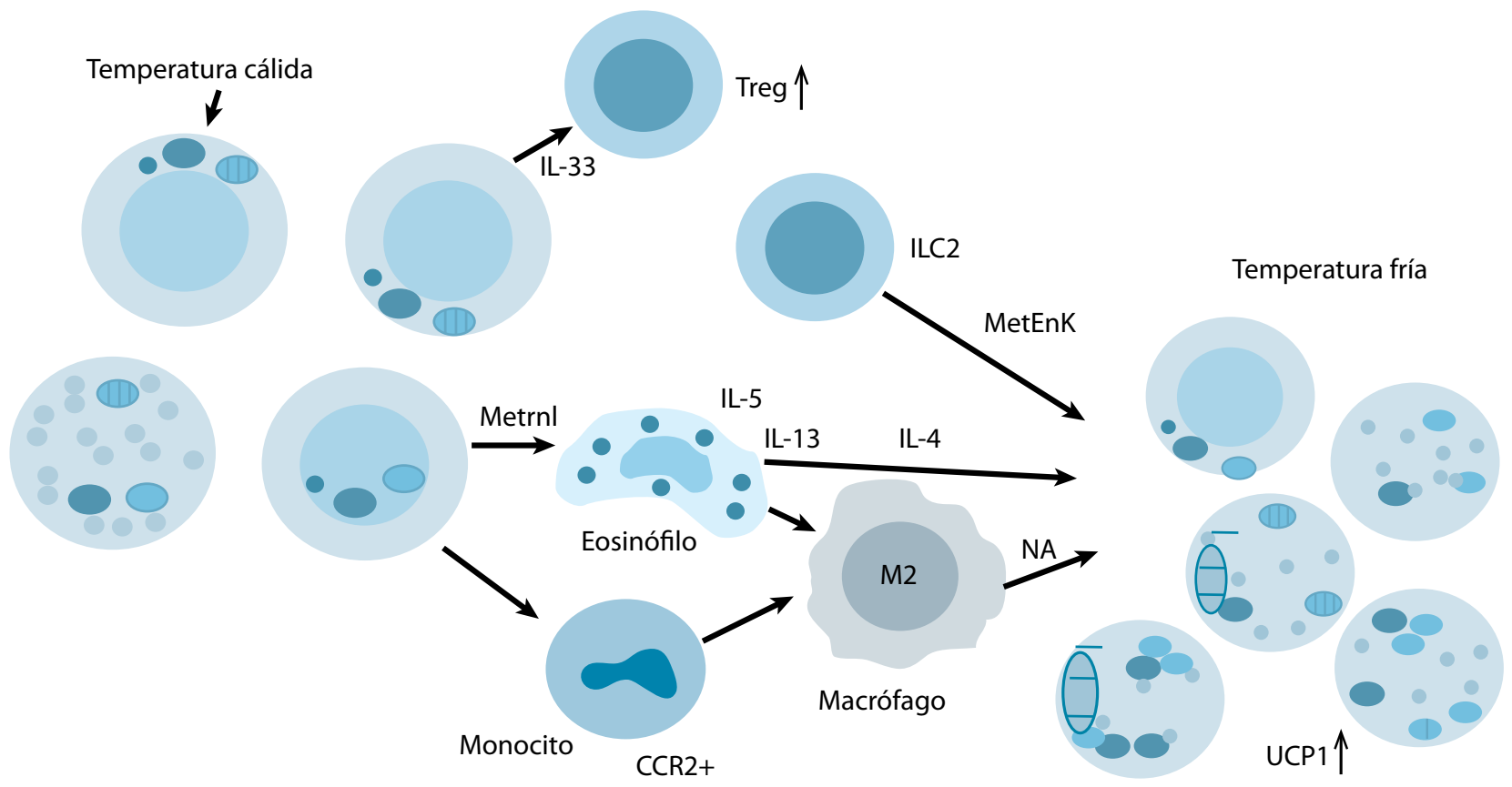


Los macrófagos y las ILC2s son mediadores importantes en la conversión de los adipocitos blancos en adipocitos beige. Este subtipo de linfocitos controla los eosinófilos y los macrófagos M2, responsables de la secreción de interleucina-5 (IL5) y de interleucina 13(IL-13), con lo que se inicia un tipo de respuesta inmune tipo 2 , que protege contra la infección por helmintos ${ }^{(25)}$. La administración de interleucina 33 (IL-33) aumenta el número de ILC2 y de consinófilos en la grasa subcutánea, con lo que se produce consumo de energía en ratones secundario a la formación de adipocitos beige a partir de los adipocitos blancos (figura 2) ${ }^{(4,6)}$. La interleucina-33 (IL-33) induce la formación de células beige a partir de precursores de las células adiposas blancas.

La secuencia productora de una mejoría metabólica originada en la formación de adipocitos beige, mediada por eosinófilos, citocinas tipo2 y macrófagos M2 está también en relación con el estado de la microbiota intestinal ${ }^{(25)}$. La administración de antibióticos a ratones en dosis capaces de modificar el microbiota intestinal y producir más adipocitos beige, tanto en ratones delgados como en obesos, produce mejoría de la glucemia y de la sensibilidad a la insulina, mediada por eosinófilos, citocinas tipo 2 y macrófagos M2. La exposición al frío altera el microbiota intestinal, remodelando el intestino y el tejido adiposo, con aumento de la superficie absortiva intestinal. La transferencia en ratones de microbiota adaptados al frío mejora la sensibilidad a la insulina y potencializa la formación de adipocitos beige. Con el uso excesivo de antibióticos diariamente en humanos se debería investigar más la obesidad y la posible relación entre la formación de los adipocitos beige y la modificación de la microbiota intestinal.

\section{Hallazgos en humanos sobre la relación entre la inmunidad y la obesidad}

Estudios extensos en roedores han demostrado que existe una estrecha relación entre la obesidad y el tejido adiposo pardo y que el sistema inmune juega un papel primordial en la regulación de este tejido graso y en la transformación de los adipocitos blancos en adipocitos beige, pero se necesita mucha investigación en humanos, para definir si en ellos ocurre algo similar. Aunque la activación de los adipocitos pardos o la inducción en la formación de células adiposas beige a partir del tejido blanco previene la obesidad producida por dieta o la genética en ratones, no siempre pueden ser extrapolados estos hallazgos a los humanos. El tejido adiposo pardo en ratones no regresa con la edad, en cambio en los humanos adultos este tejido tiene tendencia a desaparecer, la formación clásica. Otro obstáculo en la extrapolación de datos de los ratones a humanos es la diferencia entre la temperatura termoneutral y la actividad de los adipocitos pardos a nivel ambiental $\left(18-22^{\circ} \mathrm{C}\right)$. La temperatura del sitio habitual donde viven los roedores debería ser de $30^{\circ} \mathrm{C}$ comparable a la situación humana. La acti- vidad del TAP en humanos se mide generalmente con la $\left({ }^{18} \mathrm{~F}\right)$ FDG (fluorodeoxiglucosa) utilizando la emisión de positrones y TAC) PET/TAC. Como la resistencia a la insulina reduce la captación de la glucosa, sin modificación de la captación de los ácidos grasos marcados y de su capacidad oxidativa, se ha sugerido la utilización de ácidos grasos marcados en lugar de glucosa, tales como ( ${ }^{18}$ Fluoro-6-thia-heptadecanoico ácido). Se está invocando la utilización de triglicéridos con ácidos grasos marcados como trazadores ${ }^{(25)}$. Como interesante, la formación de adipocitos blancos es similar en roedores y humanos. Aunque los cambios a adipocitos beige y su contribución al consumo de energía en humanos todavía necesitan ser esclarecidos completamente, existen algunos estudios que sugieren mecanismos similares ${ }^{(25)}$. Las hormonas, las células inmunes y las citocinas que inducen la formación de adipocitos beige presentes en ratones también están presentes en los humanos.

\section{El TAP y la evolución}

Se considera que el TAP fue una defensa natural contra la hipotermia en mamíferos, aumentando la capacidad de adaptación a ambientes más fríos ${ }^{(25)}$. Temperaturas más frías se acompañaron de menor suplencia de alimentos, lo que sugiere que el TAP se podría considerar como un órgano de supervivencia.

En un principio los helmintos y parásitos produjeron infestaciones que inducían una respuesta inmune mediada por macrófago M2, reguladora de los adipocitos beige. Con las migraciones a tierras más frías, tanto los huéspedes como los helmintos, se podrían haber beneficiado del incremento de los cambios de los adipocitos blancos a beige, promotores de la sobrevida en climas más fríos ${ }^{(35)}$. Se puede apreciar cómo la inmunidad y la adaptación al frío están conectadas; cómo el hambre y las infecciones se presentaban simultáneamente, la secreción de kemocinas por el tejido adiposo blanco podría ser una ventaja en la evolución con modificaciones genotípicas para combatir la infección y acumular grasa, con el fin de aumentar la sobrevida.

Aunque el TAP parece haber perdido parte de su función, por razones relacionadas con la evolución, los jóvenes y probablemente los adultos pueden beneficiarse de la grasa parda. Esta grasa toma parte en la depuración de la glucosa y los ácidos grasos y puede servir como sistema tampón ${ }^{(25)}$.

El papel termogenético del TAB en el manejo de la energía excesiva fue demostrado en 1979 , con una dieta que propiciaba la termogénesis se obtuvo una disminución en el incremento del peso, a pesar de comida altamente calóricas ${ }^{(36)}$.

\section{Terapia}

Giordano y colaboradores ${ }^{(37)}$ revisaron las drogas que potencialmente podrían inducir los cambios beige en los adipocitos blancos. Como posibles drogas útiles en la reducción de peso están los agonistas de los receptores beta-3, aunque no 
son específicos para la grasa parda y se presentan en múltiples tejidos. Infortunadamente estos agonistas no han demostrado tener efecto importante en el balance de energía ${ }^{(25)}$. Una última generación de agonistas de los receptores beta, como el mirabegron (aprobado para vejigas hiperactivas), incrementa la actividad metabólica de los adipocitos pardos, evidenciada por aumento de la captación de estas células del $\left({ }^{18} \mathrm{~F}\right)$ FDG. Los drogas antinflamatorias por acción directa sobre el TAP o activando los cambios beige a partir del TAB, promueven perdida de la energía, útil en la terapia de la obesidad ${ }^{(37)}$.

Además de las drogas dirigidas a los receptores beta adrenérgicos, la dieta y los componentes nutricionales son capaces de modular la termogénesis y pueden ser de utilidad alternativa en el tratamiento de la obesidad. Aunque se conoce que la glucosa y los ácidos grasos son fuentes nutricionales de las células adiposas, existe abundante desconocimiento al respecto. Mientras los ácidos grasos saturados producen inflamación y son dañinos para el organismo, los ácidos omega-3 son antinflamatorios y son benéficos ${ }^{(25)}$. Se ignora si los ácidos grasos omeda-3 activan los TAP o promueven los cambios beige, lo que debe ser investigado; debe estudiarse además, si los componentes PPARgama, que son activados por los ácidos grasos poliinsaturados pueden activar el TAP o la transformación a células beige ${ }^{(38)}$. No se han investigado recientemente los efectos de carbohidratos específicos sobre la activación de los adipocitos pardos, ni los cambios de los adipocitos blancos a adipocitos beige. En el futuro debe investigarse sobre los factores que pudieran modular la termogénesis.

\section{Conclusiones}

El exceso de consumo de energía trae consigo un aumento de las células adiposas blancas, como también disminución de las adipocitos pardos, lo que produce disfunción de ambas células. El compromiso del sistema inmune en los adipocitos pardos y los blancos es necesario para la homeostasis de los dos tejidos y contribuye en el flujo de los lípidos depositados en los adipocitos blancos y en la abundante oxidación de los ácidos grasos en las células pardas y las beige.
Las células inmunes, los eosinófilos y alternativamente los macrófagos activados, juegan un papel regulador en la homeostasis de ambas células, los adipocitos blancos y los pardos. Existe extensa investigación para tratar de clarificar los factores inmunes comprometidos en sus transformaciones. Si se llegara a conocer con detalle la regulación inmune, se podría disponer de medios efectivos terapéuticos capaces de incrementar el consumo de energía en la reducción de peso. Como digno de anotar, el número de células inmunes, tanto en el tejido magro como en el adiposo, son menos en el TAP que en el TAB, lo que sugiere que las células adiposas blancas son más resistentes a la inflamación inducida por la dieta. En el momento actual se necesitaría esclarecer la interrelación entre las células inmunes y los adipocitos beige y los blancos y la secuencia de eventos que ocurre durante el desarrollo de la obesidad. La regulación del TAP no depende de una célula inmune específica sino de una interrelación inmune. Como preguntas sin contestar en la relación de las células inmunes con los adipocitos, están ${ }^{(25)}$ : ¿cuáles son las moléculas efectoras, reguladoras secretadas por los adipocitos pardos o por los precursores de los adipocitos beige? ¿Cómo actúan los adipocitos pardos en la obesidad? ¿Cuál es el papel del sistema simpático? ¿Cómo cambia la actividad de los adipocitos pardos con la edad?

En resumen, la presencia del TAP en humanos y la activación potencial de estas células o la inducción en la formación de adipocitos beige a partir de las células adiposas blancas podría utilizarse para tratar o prevenir la obesidad. La exposición al frío es hasta ahora el estímulo más efectivo para activar el sistema simpático y los adipocitos pardos. Están en investigación los mejores métodos para valerse del frío como estímulo para la activación de las células adiposas pardas, tratando de evitar exposiciones prolongadas al frío, que lesionen al individuo. El hallazgo reciente del posible papel de la inmunidad en humanos en la activación de los adipocitos pardos y beige abren prometedoras esperanzas en la utilización de estos hallazgos para promover el aumento de la actividad de ambas células, utilizables en la terapia y prevención de la obesidad. 


\section{Referencias}

1. Berrington de González A, Hartge P, Cerhan JR, et al. Body- mass index and mortality among 1,46millions White adults. N Engl J Med. 201; 363 (23): 2211-2219.

2. Yoneshiro T, Aita Mat sushita M, Kayahara T, et al.Recruited Brown adipose tissue as an atiobesity agent in humans. J Clin Invest. 2013;123 (8): 3404 3048.

3. Nguyen KD, Qiu Y, Cui X, et al.Alternatinatively activated macrophages produce catcholamines to sustain adaptive thermogenesis. Nature. 2011;480 (7375): 104-108.

4. Lee M-W, Odegaard JL, Mukundan I, et al. Activated type 2 innate linphoid cells regulate beige bage fat biogenesis. Cell 2015: 160(1-2): 74-87.

5. Qiu Y, Nguyen KD, Odegaard JL, et al. Eosinophils and type 2 cytokine signaling in macrophage orchestrate development of functional beige fat. Cells; 2014; 157 (4) 1292-1308.

6. Brestoff Jr, Kim BS, Saenz A, et al. Group 2 innate linfoid promote beiging of white adipose and limit obesity. Nature. 2014; 519 (7542): 242-246.

7. Warwick PM, Bulsby R. Influence of mild cold on 24 h energy expenditure in "normally" clothed adults. Br Nutr 2007; 63 (3): 481- 488)

8. Ivanov KP. Phisiologicalblocking of the mechanism of cold death: theoretical and experimental considerations. J Therm Biol. 2000; 25(6): 467-479.

9. Van MarkenLichtbelt WD, Vanhommerig JW, et al. Cold- activated brown adipose tissue in healthy men. N Engl J. Med. 2009; 360(15): 1500-1508.

10. Smith R. Thermoregulatory and adaptive behavior of brown adipose tissue. Science 1964; 146 (3652); 1686-1689.

11. De Jong JMA, Larsson O, Cannon B, et al. AStringent Validation of mouse adipose tissue identity markers . Am J PhysiolEndocrinolMetab. 2015; 308 (12) E 1085-E1105.

12. Nakamura K, Morrison SF. A Thermosensory pathway that controls body temperature. Nat Neurosci. 2007; 11 (1) 62-71.

13. Morrison SF, Nakamura K, Madden CJ. Central of thermogenesis in mammals. Exp Physiology. 2007; 11(1): 62-71.

14. Lowell BB, Spiegelman BM. Towards a molecular understanding of adaptive thermogenesis. Nature. 2000; 84 (1) 277-359.

15. Cannon B, NedergaardJ.Brown adipose tissue function and physiological significance. Physiol Rev. 2004; 84(1): 277-359.

16. VanMarker, Lichtbelt W. Brown adipose tissue and the regulation of nonshivering thermogenesis. CurrOpinClinNutr Metabolism Care. 2012;15(6): 547-552.

17. Cao W,Daniel KW, Robidoux , et al. p38 mitogen-activated protein Kinase is the central regulator of cyclic AMP-dependent transcription of the brown uncoupling protein I gene. Mol Cell Biol. 2004; 24(7): 3057-3067.

18. Puigserver $\mathrm{P}$, Spiegelman BM, Perixome proliferator-activated receptorgama coactivator $1 \infty(\mathrm{PGC}-1 \infty)$. Transcriptional coactivator an metabolic regulator. Endocr Rev. 2003; 24 (1): 78-90.

19. Lidell ME, Enerback S. Brown adipose tissue- a new rol in humans?Nat Rev Endicrinal. 2010; 6(6):319-325.

20. Timmons JA, Wenmaln K, Larsson O, et al. Miogenic gene expression signature establishes that brown and white adipocytes origin from distint cell lineage. Proc Natl Acad. Sci USA. 2007; 104(11): 4401-4406.
21. Liu W, Shan T, Yang X, et al. A heterogeneous lineage origin underlies the phenotypic and molecular difference of white and beige adipocytes. J Cell Sci. 2013: 136 (16): 3527- 3532.

22. Granneman JG, Li P, Zhu Z, et al . Metabolic an cellular plasticity in white adipose tissue I: effects of beta 3- adrenergic receptor activation. Am J Physiology EndocrinolMetab. 2005; 289 (4): E608- E616.

23. Barbatelly G, Murano I, Madsen L, et al. The emergence of cold-induced brown adipose in white to brown adipocyte transdifferentiation. An J PhisiolEndocrinolMetab. 2010;298 (6): E1244-E1253.

24. Cinti S. Adipocite differentiation and transdifferentiation plasticity of the adipose organ. J Endocrinol Invent. 2014; 25 (10): 15(4): 480-491.

25. Van den Berg, Andrea D van Dam, et al.Immune modulatorior of brown (ing) adipose tisue in obesity.Endocr Rev; 2017: 38: 46-68.

26. Shimizu I, Aprahamian T, Kikuchi R, et al. Vascular faction rarefaction mediate whitening of brown fat in obesity. J Clin Invest. 2014; 124 (5): 20992112.

27. Hung C-M, CalejmanCM , Sanchez-Gurmaches J, et al. Rictor /mTORC2 loss in the Myf5 lineage reprograms brown metabolism and protects mice against obesity and metabolic disease. Cell Reports . 2014: 8(1): 256-271.

28. Kooijman S, van den Berg R, Ramkisoensing A, et al. Prolonged daily light exposure increase body, fat mass trough attenuation of brown adipose tissue activity. Proc NatlSci USA. 2015, 112(21): 748-653.

29. SaitoM,Okamasu- Ogura Y, Matsushita M, et al. High incidence of metabolicactive brown adipose tissue in healthy adults humans: effects of cold exposure and adipocity. Diabetes.2009; 58(7): 1536-1531.

30. Chondronikola M, Volpi E, Borshein E, et al.Brown adipose tissue improves whole-body glucose homeostasis and insulin sensitivity in humans. Diabetes. 2014; 63 (12): 4089-4099.

31. Lee P, Smith S,Linderman J, et al. Temperature- acclimated brown adipose tissue modulates insulin sensitivity in humans. Diabetes. 2014; 63(11) 3686-3698.

32. Taky , RA, Ishai A, Truong QA, et al. Supraclavicular brown adipose ${ }^{18} \mathrm{~F}-\mathrm{FDG}$ uptake and cardiovascular disease. J Nucl Med. 2016; 57(8): 1221-1225.

33. Boon MR, Kooijman S, van Dam AD, et al. Peripheral cannabinoid 1 receptor bloocadeactivatival brown adipose tissue and dimishes dyslipidemia and obesity. FASEBJ. 2014: 28(12): 5361-5378.

34. Kooijman S, Wang Y, Parlevliet, et al. Central GLP-1 receptor signaling accelerates plasma clearance of triacylglycerol and glucose by activating brown adipose tissue in mice. Diabetologia.2015; 58 (11): 2637-2646.

35. Guigas B, Molofsky AB. A worm of one's own: how helmints modulate host adipose tissue function and metabolism trends. Parasitol. 2015:31 (9): 435441.

36. Rothwell NJ, Stock MJ. A Role for brown adipose tissue in diet inducide thermogenesis. Nature. 1979; 821 (5726): 31-35

37. Giordano A, Frontini A, Cinti S, et al. Convertible visceral fatt as a therapeutic target to curb obesity.Nat Rev Drug Discov. 2016;15(6): 405-424.

38. Varga T, Czimmerer Z, Nagy L. PPARs are a unique set of fatty acid regulate transcription factor controlling both lipid metabolism andinflmation. BiochimBiophysActa. 2011;1812:1007-1022. 